\section{Triphasic Waves Detected during Recovery from Lithium Intoxication}

Key words: triphasic waves, lithium intoxication, electroencephalogram (EEG), serum lithium levels, neurotoxicity, renal dysfunction

Lithium is widely used to treat acute mania and as maintenance therapy for bipolar disorder (1). We report a patient who presented triphasic waves on electroencephalogram (EEG) during recovery from lithium intoxication. Moreover, elevated serum lithium level decreased before EEG normalization. This suggests that there is a slight time lag between serum lithium levels and EEG indicating lithium neurotoxicity.

A 74-year-old woman had a history of manic-depressive illness and had been receiving lithium carbonate treatment (300 mg daily) for 40 years. Four months before admission, she experienced knee joint pain and began to take oral zaltoprofen ( $240 \mathrm{mg}$ daily). One month later, anorexia and hand tremor started. Her gait gradually became unsteady. She fell while walking outside and was admitted to our hospital. Neurological examination demonstrated delirium, gait disturbance with parkinsonism, hand tremor with asterixis, and myoclonus. Laboratory examination showed renal dysfunction (blood urea nitrogen (BUN) $23.3 \mathrm{mg} / \mathrm{dl}$, creatinine $1.0 \mathrm{mg} / \mathrm{dl}$, K $5.0 \mathrm{mEq} / l$, uric acid $8.4 \mathrm{mg} / \mathrm{dl}$, creatinine clearance $58.9 \mathrm{ml} / \mathrm{min}$ ) despite normal renal function one year earlier (BUN $12.8 \mathrm{mg} / \mathrm{dl}$, creatinine $0.7 \mathrm{mg} / \mathrm{dl}$ ). Blood sugar, $\mathrm{NH}_{3}$ and vitamin $\mathrm{B}_{1}$ were normal. Lumbar puncture and brain CT were unremarkable. Her skin and tongue were very dry, so fluid therapy was started $(1,500 \mathrm{ml}$ daily). On hospital day three, routine awake EEG recording demonstrated a mild excess of background slow activity in the bilateral centroparietal region (Fig. 1A), and elevated serum lithium level of $1.78 \mathrm{mEq} / l$ (therapeutic range 0.6 to $1.2 \mathrm{mEq} / l$ ) was detected. Therefore, lithium treatment was discontinued, as well as zaltoprofen. However, delirium progressed. There
A

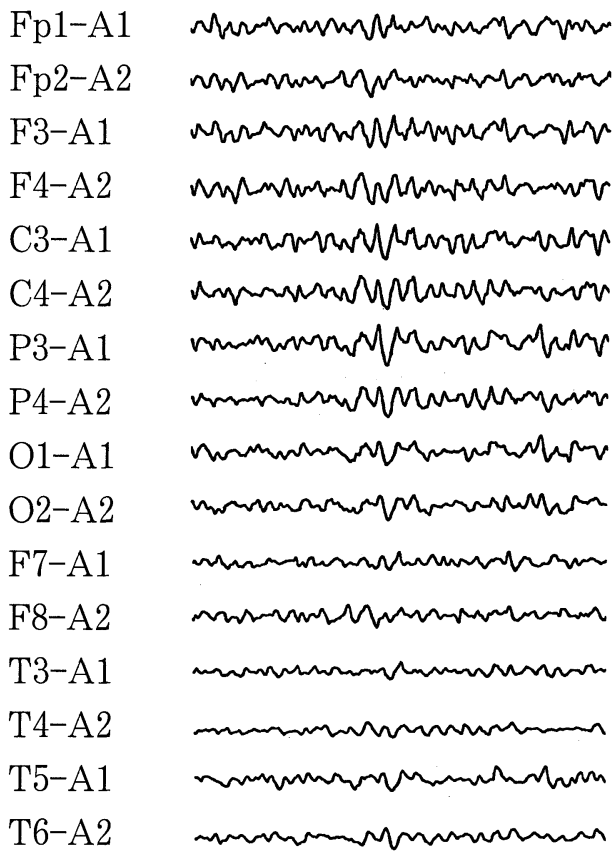

$\mathrm{B}$

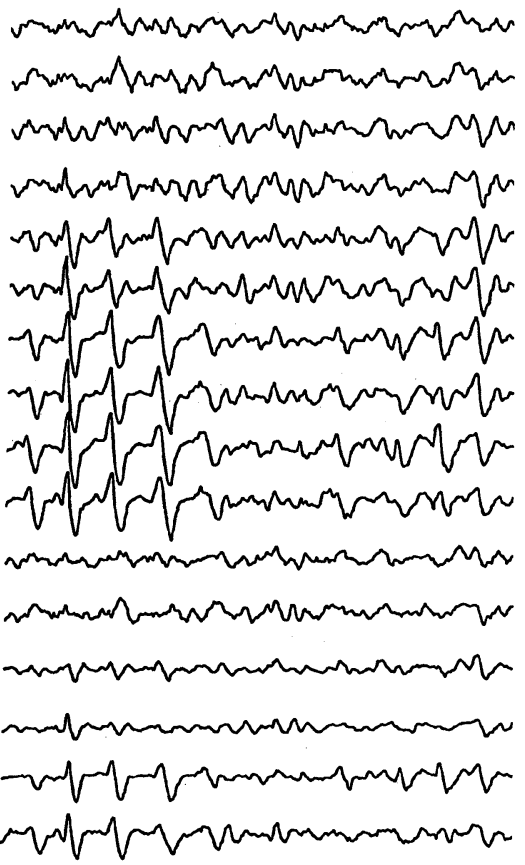

$\mathrm{C}$

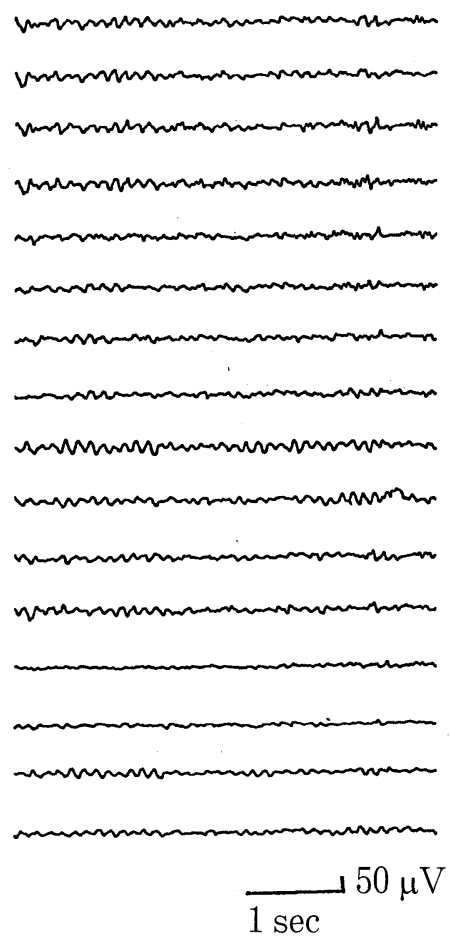

Figure 1. Routine awake EEG recordings. (A) On hospital day 3, EEG showed a mild excess of background slow activities in the bilateral centroparietal region. An elevated serum lithium level of $1.78 \mathrm{mEq} / l$ was detected. (B) EEG on hospital day 8 demonstrated high amplitude triphasic waves with intermixed theta activities in the parieto-occipital region. However, the serum lithium level was reduced to $0.55 \mathrm{mEq} / l$. (C) On hospital day 17, EEG recovered to normal alpha activity. 
were no other neuroleptic drugs administered. EEG on hospital day eight demonstrated high amplitude triphasic waves with intermixed theta activities in the parieto-occipital region (Fig. 1B). However, the serum lithium level was reduced to $0.55 \mathrm{mEq} / l$. Anorexia and skin dryness recovered and fluid therapy was stopped. On hospital day 17, her neurological status and renal function improved, and EEG recovered to normal alpha activity (Fig. 1C).

Lithium is absorbed from the gastrointestinal tract and excreted by the kidney $(2,3)$. Our patient developed renal dysfunction after administration of nonsteroidal anti-inflammatory drug (NSAID). We believe that failure of renal lithium excretion, therapeutic combination with NSAID, aging and dehydration elevated our patient's serum lithium levels $(1,3)$.

The most striking and unique feature of this case was the dissociation between EEG findings and serum lithium levels. Because, lithium is transported and accumulated into tissues and cells, lithium has longer effects on the brain than on systemic circulation. Lithium affects phosphoinositide signaling, protein kinase $\mathrm{C}$ (PKC) regulation, and the downregulation of the major $\mathrm{PKC}$ substrate myristoylated alaninerich C-kinase substrate (MARCKS) (4). Chronic reduction in MARCKS persists beyond lithium treatment discontinuation in rats. Serum lithium is, however, excreted by the kidney with a half-life time of 14 to 30 hours. Clinically, in a previously reported case of acute lithium toxicity (2), the elevated serum lithium level $(3.2 \mathrm{mEq} / l)$ decreased to $0.4 \mathrm{mEq} / l$ after repeated hemodialyses, but the patient remained comatose and died. In fact, the EEG series and serum lithium level evaluations in the present patient reflect both the lithium neurobiology and paradoxical clinical course of lithium intoxication.

We believe that delirium in this case was not related to other acute neurological disorders, e.g. cerebrovascular disease, because EEG completely recovered. Uremic encephalopathy is also denied by her mild and non-acute renal dysfunction. Regarding therapy for lithium intoxication, active treatment to promote excretion of lithium through the kidney or by hemodialysis should be continued.

While EEG studies of lithium intoxication have shown various abnormalities (5), there are few descriptions of triphasic waves. We cannot conclude that EEG is the only tool for diagnosing lithium intoxication although pathological EEG is documented with normal or decreased serum lithium levels (5) because, as in this case, timely serial evaluations of both tests should provide accurate monitoring of the disease course.

\section{Yoko SHIBASAKI WARABI*, Jiro IDEZUKA, Motoyoshi YAMAZAKI and Yoji ONISHI}

The Department of Neurology, Niigata City General Hospital, Niigata, *Present address: the Department of Neurology, Tokyo Metropolitan Neurological Hospital, Tokyo

Received for publication February 18, 2003; Accepted for publication May 15,2003

Reprint requests should be addressed to Dr. Yoko S. Warabi, the Department of Neurology, Tokyo Metropolitan Neurological Hospital, 2-6-1 Musashidai, Fuchu, Tokyo 183-0042

\section{References}

1) Kores B, Lader MH. Irreversible lithium neurotoxicity: an overview. Clin Neuropharmacol 20: 283-299, 1997.

2) Mangano WE, Montine TJ, Hulette CM. Pathologic assessment of cerebellar atrophy following acute lithium intoxication. Clin Neuropathol 16: 30-33, 1997.

3) Thomsen K, Schou M. Avoidance of lithium intoxication: advice based on knowledge about the renal lithium clearance under various circumstances. Pharmacopsychiatry 32: 83-86, 1999.

4) Lenox RH, McNamara RK, Papke RL, Manji HK. Neurobiology of lithium: an update. J Clin Psychiatry 59 (Suppl 6): 37-47, 1998.

5) Gallinat J, Boetsch T, Padberg F, Hampel H, Hermann WM, Hegerl U. Is the EEG helpful in diagnosing and monitoring lithium intoxication? A case report and review of the literature. Pharmacopsychiatry 33: 169-173, 2000. 